\title{
Tradução e adaptação transcultural do "Modified Mann Assessment of Swallowing Ability (MMASA)" para a língua portuguesa do Brasil
}

\section{Translation and cross-cultural adaptation of the "Modified Mann Assessment of Swallowing Ability (MMASA)" into Brazilian Portuguese language}

\author{
Nayara Ribeiro da Silva* \\ Jéssica Caroline Silva Ribeiro* \\ Leila Maria Gumushian Felipini ${ }^{* * *}$ \\ Cláudia Tiemi Mituuti ${ }^{* \star * *}$ \\ Gabriele Ramos de Luccas ${ }^{* * * * *}$
}

\footnotetext{
* Doutoranda do Programa de Pós-Graduação em Fonoaudiologia da Faculdade de Odontologia de Bauru. E-mail: nayararibeiro28@hotmail.com

** Pós-graduanda em Transtorno do Espectro Autista e em Intervenção ABA para autismo e Deficiência Intelectual pelo Child Behavior Institute of Miami. E-mail: jcs.ribeiro.8@gmail.com *** Doutora em Ciências pela Faculdade de Odontologia de Bauru. E-mail: leila.felipini79@gmail.com

${ }_{* * * *}$ Doutora em Ciências pela Faculdade de Odontologia de Bauru e Especialista em Disfagia e Motricidade Orofacial pelo Conselho Federal de Fonoaudiologia. E-mail: claudia.mituuti@ufsc.br

${ }_{* * * * *}$ Doutoranda do Programa de Pós-Graduação em Fonoaudiologia da Faculdade de Odontologia de Bauru. E-mail: gabriele.luccas@gmail.com
} 


\title{
Juliane Ruiz de Souza ${ }^{* *+* * * * *}$
}

\section{Marcela Maria Alves da Silva-Arone \\ Giédre Berretin-Felix ${ }^{* * * * * * * *}$}

\begin{abstract}
Resumo: No Brasil, na área da Disfagia, a escassez de instrumentos clínicos é significativa. Traduzir e adaptar instrumentos disponíveis em idiomas estrangeiros é uma forma de amenizar esse problema. Assim, este estudo buscou traduzir e adaptar transculturalmente o "Modified Mann Assessment of Swallowing Ability (MMASA)" da língua inglesa norte-americana para a língua portuguesa do Brasil, de acordo com as recomendações de Peters e Passchier (2006). O MMASA é um instrumento de rastreio desenvolvido para identificar as características de risco para a disfagia em pacientes com acidente vascular encefálico. Quatro etapas metodológicas foram conduzidas: tradução e síntese das traduções, retrotradução, banca de especialistas e pré-teste. Conceitos das áreas de Tradução e de Saúde foram discutidos. O MMASA em língua portuguesa do Brasil foi estabelecido e considerado equivalente ao original.
\end{abstract}

Palavras-chave: Tradução (Processo); Adaptação Transcultural; Fonoaudiologia; Deglutição; Rastreio.

Abstract: In Brazil, there is a significant lack of clinical assessment tools in the Dysphagia area. One way to minimize this problem is to translate and adapt assessment tools available in a foreign language. Thus, this study aimed to translate and crossculturally adapt the "Modified Mann Assessment of Swallowing Ability (MMASA)" from the North American English language into the Brazilian Portuguese language according to recommendations by Peters and Passchier (2006). The MMASA is a screening tool developed to identify the characteristics of risk for dysphagia in patients with stroke. Four methodological steps were conducted: translation and synthesis of translations, back-translation, expert committee, and pretesting. Concepts in both Translation Studies and Health areas were discussed. The MASSA in the Brazilian Portuguese language was established and considered equivalent to its original version.

Keywords: Translation (Process); Cross-cultural Adaptation; Speech-Language Pathology; Swallowing; Screening.

\footnotetext{
****** Graduada em Fonoaudiologia pela Faculdade de Odontologia de Bauru. E-mail: julianeruiz51@gmail.com

Doutora em Fonoaudiologia pela Faculdade de Odontologia de Bauru. E-mail: marcelaaronefono@gmail.com

${ }_{* * * * * * * *}$ Pós-Doutora em Distúrbios da Deglutição pela Universidade da Flórida e Livre-docente pela Universidade de São Paulo. E-mail: gfelix@usp.br
} 


\section{Introdução}

No Brasil, em determinadas áreas da Fonoaudiologia, a escassez de instrumentos clínicos é significativa (GIUSTI; BEFI-LOPES 2008). Na área de Disfagia, especificamente, nenhum dos instrumentos disponíveis e indicados para o rastreio da disfagia orofaríngea no acidente vascular encefálico (AVE) foi desenvolvido e validado no país (ALMEIDA ET AL. 2015).

Em outros países, como nos Estados Unidos da América (EUA), essa realidade é diferente (GIUSTI; BEFI-LOPES 2008; ETGES ET AL. 2014; ALMEIDA ET AL. 2015). Profissionais da área dispõem de um amplo conjunto de instrumentos de rastreio indicados para a avaliação da disfagia orofaríngea no AVE (ETGES ET AL. 2014; ALMEIDA ET AL. 2015).

Via de regra, os instrumentos de rastreio têm como função identificar, precocemente, as características sugestivas de risco para uma possível doença, condição ou agravo em qualquer indivíduo, independentemente do seu estado de saúde (MAGALHAES Junior et AL. 2013; KeRTSCHER et AL. 2014).

O "Modified Mann Assessment of Swallowing Ability (MMASA)" (ANTONIOS ET AL. 2010), por exemplo, é um instrumento de rastreio, desenvolvido e validado nos EUA, que tem como função identificar, precocemente, as características sugestivas de risco para a disfagia orofaríngea em pacientes com AVE à beira do leito. O "Modified Mann Assessment of Swallowing Ability" avalia 12 aspectos da deglutição (ANTONIOS ET AL. 2010). O seu escore máximo é de 100 pontos, sendo que qualquer valor entre 95 e 100 caracteriza uma deglutição típica, enquanto valores menores ou iguais à 94 são indicativos de risco para a disfagia orofaríngea (ANTONIOS ET AL. 2010).

A falta de instrumentos de rastreio da disfagia orofaríngea no $A V E$, como - MMASA, no Brasil, reflete diretamente na qualidade do diagnóstico fonoaudiológico, chegando a comprometer a eficácia e a eficiência dos tratamentos (GIUSTI; BEFI-LOPES 2008).

Por conseguinte, com a intenção de amenizar este problema, alguns pesquisadores brasileiros têm realizado a tradução e adaptação transcultural 
de instrumentos de rastreio da área de Disfagia desenvolvidos e disponíveis em idiomas estrangeiros (Magalhaes Junior et al. 2013; Goncalves; Remaili; Behlau 2013; AYRES ET AL. 2016).

0 processo de tradução e adaptação transcultural de instrumentos clínicos desenvolvidos em idiomas estrangeiros apresenta diversas vantagens em comparação com o processo de desenvolvimento de um novo instrumento (BEATON ET AL. 2000). Além de, evidentemente, contribuir para minimizar a falta de instrumentos disponíveis, o processo de tradução e adaptação transcultural permite a realização de estudos transculturais, favorecendo a troca de informações entre pesquisadores sem o viés das barreiras culturais e linguísticas (Guillemin; Bombardier; Beaton 1993; Beaton et al. 2000; Peters; Passchier 2006). Entretanto, a sistematização desse processo deve ser bastante rigorosa, visto que traduzir e adaptar um instrumento clínico é tão significativo e importante quanto criar um novo (REICHENHEIM; MORAES 2007).

Nesse sentido, alguns conjuntos de diretrizes específicas para tradução e adaptação transcultural de instrumentos da área da Saúde são propostos na literatura.

As diretrizes propostas por Guillemin, Bombardier e Beaton (1993), por Beaton et al. (2000) e por Peters e Passchier (2006), por exemplo, incluem orientações para que as equivalências semântica, idiomática, experiencial e conceitual entre o texto de partida e a sua tradução (texto de chegada) sejam atingidas.

As diretrizes propostas por Guillemin, Bombardier e Beaton (1993) recomendam cinco etapas para o processo de tradução e adaptação transcultural de instrumentos clínicos, sendo (1) tradução, (2) retrotradução, (3) comitê de revisão, (4) pré-teste e (5) possível adaptação dos pesos das pontuações - para os casos em que o instrumento conta com a possibilidade de atribuição de escores.

As diretrizes de Beaton et al. (2000) preconizam seis etapas para o mesmo processo, sendo (1) tradução, (2) síntese das traduções, (3) retrotradução, (4) banca de especialistas, (5) pré-teste e (6) submissão da documentação aos autores/comitê. 
Por fim, as diretrizes propostas por Peters e Passchier (2006) sugerem quatro etapas, sendo (1) tradução e síntese das traduções, (2) retrotradução, (3) banca de especialistas e (4) pré-teste.

Partindo do exposto acima, o objetivo deste estudo foi realizar a tradução e a adaptação transcultural do "Modified Mann Assessment of Swallowing Ability (MMASA)" da língua inglesa norte-americana para a língua portuguesa do Brasil, de acordo com as diretrizes propostas por Peters e Passchier (2006), visando minimizar a falta de instrumentos de rastreio disponíveis para a avaliação da disfagia orofaríngea em pacientes com acidente vascular encefálico (AVE) à beira do leito no Brasil.

\section{Aporte teórico}

Este capítulo é composto por dois subcapítulos. 0 primeiro subcapítulo examina os termos "tradução" e "adaptação" a partir da exploração e da integração científica de duas áreas distintas do conhecimento: Tradução e Saúde. O segundo, apresenta as diretrizes para tradução e adaptação transcultural de instrumentos da área da Saúde propostas por Peters e Passchier (2006) e discute, brevemente, o conceito de "competência tradutória".

\subsection{Os Conceitos de "tradução" e "adaptação" a partir da exploração e integração científica de duas áreas distintas do conhecimento: tradução e saúde}

Este estudo trata do conceito de "interdisciplinaridade", que se refere à interação entre disciplinas aparentemente distintas, e de "multidisciplinaridade", que remete à adjeção de diferentes disciplinas em 
busca de um objetivo comum, quando torna possível a exploração e a integração científica de duas áreas distintas do conhecimento: tradução e saúde.

A terminologia e o vocabulário utilizados nas diferentes áreas do conhecimento que se inter-relacionam nem sempre é coincidente (COUTO 2003; Jesus; BARRos 2005; KRIEGer 2006A; KRIEGER 2006B). Em casos como esse, portanto, o pesquisador deve tomar um cuidado especial com a escolha e com a conceituação de termos (CoUto 2003; JESUs; BARROs 2005; KRIEGER 2006B).

Os termos "tradução" e "adaptação transcultural" empregados em publicações vinculadas à área da Saúde, por exemplo, problematizam o próprio ato de traduzir. Para o tradutor, adaptar (transculturalmente) um texto já é, em essência, a função de qualquer tradução (BASSNETT 2003; PARAGUASSU; FinATTO 2020).

$\mathrm{Na}$ área dos Estudos da Tradução, a tradução pode ser definida como processo em que um texto escrito em uma determinada língua é reescrito em outra língua, considerando as situações de produção do texto de partida, as situações de recepção do texto de chegada e as diferenças linguístico-culturais entre os dois sistemas linguísticos distintos (Leal 2006; Paraguassu; Finatto 2020). A adaptação, por sua vez, pode ser definida como modalidade tradutória (BARBOSA 2004; AUBERT 1998), intrínseca à tradução, empregada nos casos em que toda uma situação referida no texto de partida não existe na realidade extralinguística do receptor do texto de chegada e, por isso, precisa ser recriada ou substituída por uma outra situação existente e equivalente na realidade extralinguística desse receptor (BARBOSA 2004).

$\mathrm{Na}$ área da Saúde, entretanto, a tradução é entendida como processo puramente literal, em que um texto escrito em uma determinada língua é reescrito em outra língua, sem considerar fatores extralinguísticos. A adaptação, por sua vez, é interpretada como processo que sucede a tradução, em que os itens literalmente traduzidos são adaptados (modificados) com a intensão de soarem naturais à realidade extralinguística do receptor do texto de chegada (Guillemin; Bombardier; Beaton 1993; Beaton et al. 2000; Wild et al. 2005; Peters; Passchier 2006; Reichenheim; Moraes 2007). 
A área da Saúde, portanto, transforma aquilo que para o tradutor é definido e entendido unicamente como “tradução" em “tradução + adaptação transcultural” (AARONSON ET AL. 2002).

Embora se saiba que, de fato, a adaptação é intrínseca à tradução (BARBOSA 2004), os termos "tradução" e "adaptação transcultural” foram utilizados no título e no decorrer deste estudo, devido ao seu vínculo com a área da Saúde.

\subsection{Tradução e adaptação transcultural de instrumentos da área da Saúde}

Historicamente, o processo de tradução e adaptação transcultural de instrumentos desenvolvidos em idiomas estrangeiros se detinha à simples tradução literal do original ou, excepcionalmente, à comparação dessa tradução literal a uma retrotradução (SILVA; FELIPINI 2018).

Há algum tempo, entretanto, pesquisadores vêm sugerindo que o processo de tradução e adaptação transcultural de instrumentos da área da Saúde seja uma combinação da tradução literal de palavras de um idioma para o outro com a adaptação meticulosa do texto de partida para o contexto cultural e o estilo de vida do receptor do texto de chegada (GUILLEMIN; Bombardier; Beaton 1993; Beaton et al. 2000; Wild et al. 2005; Peters; Passchier 2006; REICHENHEIM; MORAES 2007).

Além disso, pesquisadores têm salientado a imprescindibilidade da atuação de tradutores profissionais durante a realização de toda tarefa tradutória (PETERS; PASSCHIER 2006), porque reconhecem que, embora qualquer falante bilíngue possua competência bilíngue no par de línguas em que se comunica, nem todo falante bilíngue possui competência tradutória (PAGANO; Magalhães; Alves 2005; Albir 2017; Paraguassu; Finatto 2020). 


\subsubsection{Diretrizes para tradução e adaptação transcultural de instrumentos da área da Saúde}

O estudo de Peters e Passchier (2006) apresenta uma revisão de algumas das principais diretrizes para tradução e adaptação transcultural de instrumentos da área da Saúde - como as propostas por Guillemin, Bombardier e Beaton (1993), por Beaton et al. (2000) e por Aaronson et al. (2002) - e defende que todo processo de tradução e adaptação transcultural de instrumentos clínicos, além de norteado por uma diretriz específica, deve ser detalhadamente descrito quando publicado, a fim de garantir o rigor e a qualidade da tradução e de padronizar o processo em diferentes países (PETERS; PASSCHIER 2006).

Para Peters e Passchier (2006), idealmente, os processos de tradução e adaptação transcultural de instrumentos da área da Saúde devem: (1) realizar traduções e retrotraduções, (2) seguir diretrizes específicas, (3) avaliar a qualidade e a equivalência da tradução e (4) realizar o teste piloto. Sendo assim, Peters e Passchier (2006) recomendam quatro etapas para tradução e adaptação transcultural de instrumentos, sendo (1) tradução e síntese das traduções, (2) retrotradução, (3) banca de especialistas e (4) pré-teste.

Para a etapa de tradução e síntese das traduções, Peters e Passchier (2006) recomendam que pelo menos duas traduções do instrumento sejam feitas do idioma de partida para o idioma de chegada por dois tradutores cuja língua materna seja a mesma do receptor do texto de chegada. Em seguida, Peters e Passchier (2006) orientam que os tradutores, junto dos autores do estudo, compilem as traduções em uma única versão consenso. Além disso, os autores recomendam que os tradutores envolvidos nesta etapa tenham ampla experiência em tradução para a área da Saúde e saibam dos objetivos e dos conceitos do estudo.

Para a etapa de retrotradução, Peters e Passchier (2006) orientam que pelo menos uma retrotradução do instrumento seja feita do idioma de chegada para o idioma de partida por um tradutor cuja língua materna seja a mesma do 
produtor do texto de partida. Em seguida, Peters e Passchier (2006) recomendam que todos os tradutores envolvidos no processo até o momento analisem e comparem as versões original e retrotraduzida do instrumento, procurando por itens que possam ter sido traduzidos inadequadamente.

Para a etapa de banca de especialistas, Peters e Passchier (2006) recomendam que pelo menos dois profissionais (da mesma área do instrumento) comparem as versões original e traduzida do instrumento, procurando por itens que possam ter sido traduzidos inadequadamente. Além disso, Peters e Passchier (2006) recomendam que os profissionais envolvidos nesta etapa proponham traduções alternativas para os itens classificados como inadequados.

Peters e Passchier (2006) explicam que a etapa de pré-teste é fundamental para que a equivalência entre o texto de partida e o texto de chegada seja alcançada. Nessa etapa, o instrumento traduzido deve ser aplicado a um número de sujeitos da população-alvo (receptor do texto de chegada), com a finalidade de verificar se o texto de chegada é compreensível e culturalmente equivalente à realidade linguística e extralinguística do seu receptor (PETERS; PASSCHIER 2006).

As diretrizes propostas por Guillemin, Bombardier e Beaton (1993), por Beaton et al. (2000) e por Peters e Passchier (2006) incluem orientações para que sejam atingidas as equivalências semântica, idiomática, experiencial e conceitual entre o texto de partida e a sua tradução (texto de chegada).

De acordo com Beaton et al. (2000), a equivalência semântica diz respeito à relação entre significantes (palavras, frases, sinais e símbolos) e significados (o que eles representam) e busca equacionar as dificuldades causadas por significados múltiplos.

A equivalência idiomática trata das dificuldades em traduzir expressões idiomáticas e coloquialismos do idioma do texto de partida para o idioma do texto de chegada (BEATON ET AL. 2000). Nesses casos, expressões equivalentes no idioma do texto de chegada devem ser usadas.

A equivalência experimental busca fazer com que os termos utilizados no texto de chegada sejam coerentes com as experiências vivenciadas pelo seu 
receptor. Beaton et al. (2000) definem esse tipo de equivalência como a tradução dos hábitos da vida diária de uma determinada cultura e explicam que uma tarefa específica descrita no texto de partida pode não ser experimentada pelo receptor do texto de chegada; por exemplo, o uso do garfo na alimentação que não é comum a todas as culturas.

Por fim, a equivalência conceitual busca validar o conceito explorado no texto de partida nas experiências vividas pelo receptor do texto de chegada, visto que algumas palavras podem apresentar equivalência semântica, mas não conceitual (BEATON ET AL. 2000). O conceito de uma palavra pode variar de idioma para idioma e de cultura para cultura. Beaton et al. (2000) citam como exemplo o conceito da palavra "família" que pode variar entre culturas, como família nuclear ou família extensa.

\subsubsection{Competência tradutória}

Conforme descrito anteriormente, pesquisadores têm salientado a imprescindibilidade da atuação de tradutores profissionais durante a realização de toda tarefa tradutória (Peters; PASSCHIER 2006), porque reconhecem que, embora qualquer falante bilíngue possua competência bilíngue no par de línguas em que se comunica, nem todo falante bilíngue possui competência tradutória (Pagano; Magaliães; Alves 2005; Albir 2017; Paraguassu; Finatto 2020).

Pagano, Magalhães e Alves (2005) explicam que a competência tradutória é um sistema subjacente de conhecimentos, habilidades e atitudes necessários para se traduzir. A competência tradutória é um conhecimento especializado, composto de cinco subcompetências, sendo elas a bilíngue, a extralinguística, a instrumental, a estratégica e a de conhecimentos sobre a tradução; além de componentes psicofisiológicos.

Segundo Pagano, Magalhães e Alves (2005), a subcompetência bilíngue é integrada por conhecimentos pragmáticos, textuais e léxico-gramaticais necessários para a comunicação em um par de idiomas. A subcompetência 
extralinguística, por sua vez, é composta por conhecimentos culturais e enciclopédicos.

Pagano, Magalhães e Alves (2005) definem a subcompetência instrumental como um conjunto de conhecimentos procedimentais relacionados ao uso de ferramentas (softwares) e de tecnologias da informação e comunicação (TICs) aplicadas à tradução.

A subcompetência estratégica busca garantir a eficácia do processo tradutório enquanto opera para identificar os problemas de uma tradução e as soluções para esses mesmos problemas. A subcompetência estratégica tem caráter central, visto que tem como função controlar e avaliar o processo tradutório, além de coordenar as diferentes subcompetências e compensar deficiências entre elas (PAGANO; MAGALHÃES; ALVES 2005).

Por fim, a subcompetência de conhecimentos sobre a tradução abrange todos os conteúdos relacionados à Teoria da Tradução: princípios como o da unidade de tradução, das diferentes modalidades tradutórias e dos diferentes processos, métodos e procedimentos tradutórios; além dos aspectos profissionais, como o da ética em Tradução (PAGANO; MAGALHÃES; ALVES 2005).

De acordo com Pagano, Magalhães e Alves (2005), os componentes psicofisiológicos estão relacionados às capacidades cognitivas do tradutor, como a capacidade de memória, de percepção, de atenção e de concentração, e às atitudes do tradutor durante a execução da tarefa tradutória, como a curiosidade, a perseverança, o rigor, o senso crítico e a confiança.

\section{Metodologia}

Este estudo foi aprovado pelo Comitê de Ética em Pesquisa em Seres Humanos da Faculdade de Odontologia de Bauru - Universidade de São Paulo (CAAE: 38572414.8 .0000 .5417$)$ e todos os participantes assinaram o Termo de 
Consentimento Livre e Esclarecido.

Mediante a autorização dos autores do instrumento, o "Modified Mann Assessment of Swallowing Ability (MMASA)" (ANTONIOS ET AL. 2010) foi traduzido da língua inglesa norte-americana para a língua portuguesa do Brasil, de acordo com as recomendações de Peters e Passchier (2006).

$\mathrm{Na}$ primeira etapa, foram realizadas duas traduções iniciais independentes (T1 e T2) da língua inglesa norte-americana para a língua portuguesa do Brasil por dois tradutores nativos de língua portuguesa. Em seguida, os dois tradutores, junto dos autores deste estudo, compilaram as traduções (T1 e T2) em uma única versão consenso (VC).

Na segunda etapa, a VC foi retrotraduzida da língua portuguesa do Brasil para a língua inglesa norte-americana por um tradutor nativo de língua inglesa norte-americana, totalmente cego para a versão original do instrumento. Em seguida, os três tradutores realizaram uma análise e verificação comparadas da retrotradução $(\mathrm{RT})$ e do instrumento original e estabeleceram a versão prévia (VP) do MMASA em língua portuguesa do Brasil. Para isso, cada participante, com base no próprio conhecimento prévio das línguas (portuguesa do Brasil e inglesa norte-americana), destacou na RT aquilo que considerava ser uma tradução problemática e passível de discussão. Todos os itens destacados foram analisados, discutidos e readequados.

$\mathrm{Na}$ terceira etapa, três fonoaudiólogos bilíngues com experiência em disfagia orofaríngea analisaram a VP com base no instrumento original e estabeleceram a versão pré-final (VPF) do MMASA em língua portuguesa do Brasil. Para isso, a VP foi dividida em 15 seções e cada participante, individualmente, atribuiu uma pontuação para cada seção, sendo “-1 = seção não equivalente", “0 seção equivale” e "1 seção muito equivalente”. Todas as seções pontuadas como “-1" foram analisadas, discutidas e readequadas.

$\mathrm{Na}$ quarta etapa, a clareza e a equivalência da VPF foram verificadas e a versão final (VF) do MMASA em língua portuguesa do Brasil foi estabelecida. Para isso, a VPF foi aplicada em 12 pacientes voluntários do Hospital de Base de Bauru (HBB) - sendo oito mulheres e quatro homens, entre 62 e 81 anos de idade, com quadro agudo de acidente vascular encefálico (AVE) isquêmico, sem 
diagnóstico clínico de demência e sem queixa prévia de disfagia orofaríngea por dois fonoaudiólogos do HBB. Ao todo, foram realizadas 24 aplicações; individualmente, cada fonoaudiólogo aplicou a VPF do MMASA uma vez em cada paciente voluntário, mantendo um intervalo de duas horas entre as aplicações.

Os autores do estudo preestabeleceram que, para que a VPF do MMASA fosse considerada clara e equivalente, o nível de concordância dos resultados de suas aplicações entre os avaliadores deveria ser "excelente" de acordo com o referencial proposto por Fleiss (1986), conforme demostra o Quadro 1. O nível de concordância entre os avaliadores foi mensurado por meio do coeficiente de correlação intraclasse $(\mathrm{CCl})^{1}$. 0 cálculo do $\mathrm{CCl}$ foi realizado por meio do programa Statistical Package for the Social Sciences (SPSS), versão 26.

Quadro 1: Referencial do coeficiente de correlação intraclasse $(\mathrm{CCl})$ proposto por Fleiss (1986).

Quadro 1

\begin{tabular}{|l|l|}
\hline $\mathrm{CCl}<0,4$ & Pobre \\
\hline $0,4 \leq \mathrm{Cl}<0,75$ & Satisfatório \\
\hline $\mathrm{CCl} \geq 0,75$ & Excelente \\
\hline
\end{tabular}

Fonte: Elaborado pelo autor.

\section{Resultados e Discussão}

Na primeira etapa, ao todo, 108 itens foram traduzidos da língua inglesa norte-americana para a língua portuguesa do Brasil. Desses 108 itens, 17 foram traduzidos exatamente iguais na T1 e na T2 e 91 apresentaram divergências

\footnotetext{
${ }^{1} \mathrm{O}$ Coeficiente de Correlação Intraclasse $(\mathrm{CCl})$ é um parâmetro amplamente utilizado em pesquisas científicas para medir a correlação entre amostras de avaliações de dois ou mais avaliadores quando há uma variável quantitativa (COSTA 2011). A correlação de uma variável é medida de 0 a 1: quanto mais próxima de 1, mais perfeita é a relação entre as duas medidas; quanto mais próxima do 0 , pior ela é (COSTA 2011).
} 
entre a T1 e a T2.

$\mathrm{Na}$ VC, dos 17 itens traduzidos exatamente iguais na T1 e na T2, apenas um foi readequado. E, dos 91 itens divergentes entre a T1 e a T2, 27 foram mantidos como na T1, 15 foram mantidos como na T2 e 49 foram readequados.

Tanto a readequação do item traduzido exatamente igual na T1 e na T2 quanto as readequações dos itens divergentes entre a T1 e a T2 foram feitas por meio da comparação entre o instrumento original, a T1 e a T2, com base no conhecimento prévio dos tradutores. Todas as readequações buscaram por melhores equivalentes tradutórios.

O item "Task: Observe patient's control of saliva; note any escape of secretions from the side of the mouth", por exemplo, foi traduzido na T1 como "Tarefa: Observar o controle de saliva do paciente, notar qualquer saída de secreção na lateral da boca" e na T2 como "Rotina: Observar o controle da salivação do paciente; notar qualquer escape de secreções pelo lado da boca". $\mathrm{Na}$ VC, o item foi readequado para "Tarefa: Observe o controle de saliva do paciente, note qualquer escape de secreção pela lateral da boca”.

E o item "Task: Assess tongue movement" foi traduzido na T1 como "Tarefa: Avaliar o movimento da língua" e na T2 como "Rotina: Avaliar a movimentação da língua”. Na VC, o item foi readequado para "Tarefa: Avalie o movimento da língua”.

É possível observar que algumas das readequações feitas na VC do MMASA buscaram, principalmente, estabelecer um paralelismo sintático entre os itens traduzidos (DUARTE 2020). Na VC, as palavras no tempo presente do modo indicativo - como “observar”, “avaliar” e "notar” -, presentes nas sentenças que expressam comando, foram substituídas por verbos do modo imperativo como "observe”, “avalie” e “note”. Em língua portuguesa, o modo imperativo é frequentemente substituído pelo tempo presente do modo indicativo como forma de suavizar a maneira como são dados os comandos; entretanto, o modo imperativo é o mais comumente usado para expressar comando (NEVES 2020A).

O item “4. Expressive Dysphasia” foi traduzido na T1 como "4. Disfagia de Expressão” e na T2 como “4. Disfasia Expressiva”. Na VC, o item foi readequado para “4. Afasia de Expressão”. 
É possível constatar que algumas das readequações feitas na VC do MMASA também buscaram assegurar o uso da linguagem técnica e recorrente em publicações científicas da área da Fonoaudiologia (JESUs; BARROS 2005; Paraguassu; Finatto 2020). Apesar de "disfasia", na T2, ser literalmente equivalente à "dysphasia", nesse caso, o termo técnico e recorrente em publicações científicas da área é "afasia”. Em produções científicas originalmente escritas em língua inglesa norte-americana, o distúrbio definido como "dysphasia" (SHIEL JUNIOR 2018) refere-se ao mesmo distúrbio definido como "afasia" em artigos científicos originalmente escritos em língua portuguesa do Brasil (AFASIA 2020): "afasia” é um distúrbio de linguagem que afeta a capacidade de comunicação do indivíduo (MASSAUD 2020). Na T1, "disfagia” não é equivalente à "dysphasia": "disfagia” é "dificuldade de deglutir" (DISFAGIA 2020).

$\mathrm{Na}$ segunda etapa, ao todo, 108 itens foram retrotraduzidos da língua portuguesa do Brasil para a língua inglesa norte-americana. Desses 108 itens, 20 foram destacados por serem considerados itens problemáticos e passíveis de discussão. Todos os itens destacados foram analisados, discutidos e readequados. Todas as readequações buscaram por melhores equivalentes tradutórios.

0 item "2 = Gross weakness or unable to perform", por exemplo, foi traduzido na VC como " 2 = Fraqueza significativa ou incapacidade de realizar" e na RT como " 2 = Significant weakness or incapable of performing". Na VP, o item foi readequado para " 2 = Muita fraqueza ou incapacidade realizar o movimento".

E o item " 2 = No elevation of palate or unable to perform" foi traduzido na VC como " 2 = Sem elevação do palato ou incapaz de realizar" e na RT como "2 = No elevation of the palate or incapable of performing". Na VP, o item foi readequado para " 2 = Sem elevação do palato ou incapaz de realizar o movimento".

É possível verificar que algumas das readequações feitas na VP do MMASA buscaram, principalmente, adequar os itens à gramática normativa da língua portuguesa do Brasil. O verbo "realizar" é um verbo transitivo direto (REALIZAR 
2020); isto é, um verbo que, tendo sentido incompleto, necessita de um complemento verbal para completar o seu sentido - nesse caso, um objeto direto (NEVES 2020B): “o movimento”.

$\mathrm{Na}$ terceira etapa, conforme descrito na metodologia deste estudo, três fonoaudiólogos bilíngues com experiência em disfagia orofaríngea analisaram a VP do MMASA com base no instrumento original. A VP foi dividida em 15 seções e cada participante, individualmente, atribuiu uma pontuação para cada seção, sendo "-1 = seção não equivalente", " 0 = seção equivale" e " 1 = seção muito equivalente". Dessas 15 sessões, apenas uma foi pontuada como “-1" e readequada. A readequação buscou por melhores equivalentes tradutórios.

O Quadro 2 apresenta o resultado das avaliações de cada seção da versão prévia (VP) do "Modified Mann Assessment of Swallowing Ability (MMASA)". Quadro 2

\begin{tabular}{|c|c|c|c|}
\hline Seção & $\begin{array}{c}\text { Pontuação } \\
\text { atribuída pelo } \\
\text { Avaliador 1 }\end{array}$ & $\begin{array}{c}\text { Pontuação } \\
\text { atribuída pelo } \\
\text { Avaliador 2 }\end{array}$ & $\begin{array}{c}\text { Pontuação } \\
\text { atribuída pelo } \\
\text { Avaliador 3 }\end{array}$ \\
\hline 1 & 1 & 1 & 0 \\
\hline 2 & 1 & 1 & 1 \\
\hline 3 & 1 & 0 & 1 \\
\hline 4 & 1 & 0 & 1 \\
\hline 5 & -1 & -1 & 0 \\
\hline 6 & 1 & 1 & 1 \\
\hline 7 & 1 & 0 & 1 \\
\hline 8 & 1 & 0 & 0 \\
\hline 9 & 0 & 0 & 1 \\
\hline 10 & 1 & 1 & 0 \\
\hline 11 & 1 & 1 & 1 \\
\hline 12 & 1 & 1 & 0 \\
\hline 13 & 1 & 0 & 0 \\
\hline 14 & 0 & 0 & 1 \\
\hline 15 & 1 & 1 & \\
\hline
\end{tabular}

Fonte: Elaborado pelo autor.

A seção cinco foi pontuada como "-1" devido à problemas no item " 2 = 
Suspected infection / frequent suctioning / respirator dependent".

0 item " 2 = Suspected infection / frequent suctioning / respirator dependent" foi traduzido na VP como " 2 = Suspeita de infecção / sucção frequente / dependência do respirador". Na VPF, o item foi readequado para "2 = Suspeita de infecção / aspiração frequente / dependência do respirador".

É possível observar que a readequação feita na VPF do MMASA buscou assegurar o uso da linguagem técnica e recorrente em publicações científicas da área da Fonoaudiologia (Jesus; BarRos 2005; PARAgUaSSU; FinatTo 2020). Apesar de "sucção", na VP, ser literalmente equivalente a "suctioning", nesse caso, o termo técnico e recorrente em publicações científicas da área é "aspiração". Em produções científicas originalmente escritas em língua inglesa norteamericana, o procedimento definido como "suctioning" (SINHA; FITZGERALD 2020) refere-se ao mesmo procedimento definido como "aspiração" em artigos científicos originalmente escritos em língua portuguesa do Brasil (ASPIRAÇão DO TRATO RESPIRATÓRIO 2020): o procedimento de "aspiração" consiste na remoção de secreções do trato respiratório (ASPIRAÇÃO dO TRATO RESPIRATóRIO 2020).

Além disso, ao analisar estatisticamente o Quadro 2, é possível verificar que $62 \%$ das avaliações da VP do MMASA foram iguais à " 1 = seção muito equivalente", $33 \%$ foram iguais à " 0 = seção equivale" e $4 \%$ foram iguais à "-1 = seção não equivalente". Estes dados demonstram que a VP foi considerada, sobretudo, muito equivalente ao instrumento original, o que permitiu que a VPF do MMASA fosse estabelecida e que o pré-teste (quarta etapa) fosse realizado.

Na quarta etapa, conforme descrito na metodologia deste estudo, a VPF do MMASA foi aplicada em 12 pacientes voluntários do Hospital de Base de Bauru (HBB) - sendo oito mulheres e quatro homens, entre 62 e 81 anos de idade, com quadro agudo de acidente vascular encefálico (AVE) isquêmico, sem diagnóstico clínico de demência e sem queixa prévia de disfagia orofaríngea por dois fonoaudiólogos do HBB. Ao todo, foram realizadas 24 aplicações. Individualmente, cada fonoaudiólogo aplicou a VPF uma vez em cada paciente voluntário, mantendo um intervalo de duas horas entre as aplicações.

O Quadro 4 apresenta uma síntese da caracterização da amostra e as pontuações obtidas a partir das avaliações realizadas com a VPF do "Modified 
Mann Assessment of Swallowing Ability (MMASA)".

Quadro 3

\begin{tabular}{|c|c|c|c|c|}
\hline Sujeito & Gênero & Idade & $\begin{array}{c}\text { Pontuação do MMASA - } \\
\text { Avaliação 1 }\end{array}$ & $\begin{array}{c}\text { Pontuação do MMASA - } \\
\text { Avaliação 2 }\end{array}$ \\
\hline 1 & $\mathrm{~F}$ & 81 & 63 & 60 \\
\hline 2 & $\mathrm{~F}$ & 79 & 60 & 63 \\
\hline 3 & $\mathrm{~F}$ & 68 & 94 & 96 \\
\hline 4 & $\mathrm{~F}$ & 64 & 100 & 94 \\
\hline 5 & M & 62 & 99 & 97 \\
\hline 6 & $\mathrm{~F}$ & 77 & 99 & 94 \\
\hline 7 & M & 70 & 98 & 93 \\
\hline 8 & M & 67 & 75 & 77 \\
\hline 9 & M & 79 & 96 & 96 \\
\hline 10 & $\mathrm{~F}$ & 74 & 100 & 100 \\
\hline 11 & $\mathrm{~F}$ & 67 & 98 & 96 \\
\hline 12 & $\mathrm{~F}$ & 77 & 96 & 96 \\
\hline
\end{tabular}

Fonte: Elaborado pelo autor.

Foi preestabelecido que, para que a VPF fosse considerada clara e equivalente, o nível de concordância dos resultados de suas aplicações entre os avaliadores deveria ser "excelente" de acordo com o referencial proposto por Fleiss (1986).

O nível de concordância entre os avaliadores foi mensurado por meio do coeficiente de correlação intraclasse $(\mathrm{CCl})$.

O $\mathrm{CCl}$ é uma das ferramentas estatísticas mais utilizadas para a mensuração da confiabilidade de medidas (SHROUT; FleISS 1979). Conforme descrito anteriormente, o $\mathrm{CCl}$ é um parâmetro amplamente utilizado em pesquisas científicas para medir a correlação entre amostras de avaliações de dois ou mais avaliadores quando há uma variável quantitativa (COSTA 2011). A correlação de uma variável é medida de 0 a 1: quanto mais próxima de 1 , mais perfeita é a relação entre as duas medidas; quanto mais próxima de 0 , pior ela é (COSTA 2011).

$\mathrm{Na}$ área da Saúde, por exemplo, pesquisadores utilizam o $\mathrm{CCl}$ para medir 
a precisão de instrumentos de avaliação clínica (CLAPPER; WOLF 1988; LUFT ET AL. 2008), assim como neste estudo.

$\mathrm{O}$ resultado do cálculo do $\mathrm{CCl}$ foi igual à 0,89 . Uma vez que 0,89 é maior ou igual à 0,75 (FLEISS 1986), a VPF do MMASA foi considerada clara e equivalente e a VF do MMASA foi estabelecida, conforme demostra o Apêndice 1.

Cabe ressaltar que o chamado "pré-teste" do processo de tradução e adaptação transcultural de instrumentos da área da Saúde equivale ao teste de validade do conteúdo linguístico do instrumento (BEATON ET AL. 2000). O préteste busca verificar se a adaptação transcultural realizada durante o processo de tradução e adaptação transcultural funciona na realidade linguística e, principalmente, extralinguística do receptor do texto de chegada e não confere nenhuma validade de propriedades psicométricas ao instrumento (BEATON ET AL. 2000).

\section{Conclusão}

A tradução e adaptação transcultural do “Modified Mann Assessment of Swallowing Ability (MMASA)" da língua inglesa norte-americana para a língua portuguesa do Brasil foi realizada de acordo com as recomendações de Peters e Passchier (2006).

A versão final (VF) do “Modified Mann Assessment of Swallowing Ability (MMASA)" traduzida da língua inglesa norte-americana para a língua portuguesa do Brasil manteve a estrutura da versão original do "Modified Mann Assessment of Swallowing Ability (MMASA)". O título do instrumento em língua portuguesa do Brasil é "Protocolo Mann de Avaliação da Habilidade de Deglutição Modificado (MMASA)".

Para identificar, precocemente, as características sugestivas de risco para a disfagia orofaríngea em pacientes brasileiros com AVE à beira do leito, entretanto, é recomendável que o Protocolo Mann de Avaliação da Habilidade de Deglutição Modificado (MMASA) tenha suas propriedades psicométricas devidamente validadas. 


\section{Referências bibliográficas}

AARONSON, N. ET AL. Assessing health status and quality-of-life instruments: attributes and review criteria. Quality of Life Research, v. 11, n. 3, Oxford, may. 2002, pp. 193-205.

AFASIA. In: Michaelis Dicionário. 2020. Disponível em: <https://michaelis.uol.com.br/moderno-portugues/busca/portuguesbrasileiro/afasia/>. Acesso em: 22 mai 2020.

ALBIR, A. H. Traducción y Traductología: Introducción a la Traductología. Editora Cátedra, 2017.

ALMEIDA, T. M. de ET AL. Screening tools for oropharyngeal dysphagia in stroke. Audiology - Communication Research, v. 20, n. 4, São Paulo, dec. 2015, pp. 361-370.

Antonios, N. et AL. Analysis of a Physician Tool for Evaluating Dysphagia on an Inpatient Stroke Unit: The Modified Mann Assessment of Swallowing Ability. Journal of Stroke and Cerebrovascular Diseases, v. 19, n. 1, New York, jan./feb. 2010, pp. 49-57.

Aspiração do Trato Respiratório. In: Portal Educação. 2020. Disponível em: <https://www.portaleducacao.com.br/conteudo/artigos/farmacia/as piracao-do-trato-respiratorio/30283>. Acesso em: 23 mai 2020.

AUBERT, F. H. Modalidades de tradução: teoria e resultados. TradTerm, v. 5, n. 1, jun. 1998, pp. 99-128.

AYRES, A. ET AL. Tradução e adaptação cultural do swallowing disturbance questionnaire para o português-brasileiro. Revista CEFAC, v. 18, n. 4, São Paulo, ago. 2016, pp. 828-834.

BASSNETT, S. Estudos de tradução fundamentos de uma disciplina. Tradução: Vivina de Campos Figueiredo. Lisboa: Fundação Calouste Gulbenkian, 2003. 
BEATON, D. E ET AL. Guidelines for the process of cross-cultural adaptation of self-report measures. Spine, v. 25, n. 24, Philadelphia, dec. 2000, pp. 3186-3191.

ClapPer, M. P.; Wolf, S. L. Comparison of the reliability of the orthoranger and the standart goniometer for assessing active lower extremity range of motion. Physical Therapy, v. 68, n. 2, Alexandria, feb. 1988, pp. 214218.

Costa, L. G. H. Coeficiente de correlação intraclasse: comparação entre métodos de estimação clássico e bayesianos. Trabalho de Conclusão de Curso (Graduação em Estatística) - Universidade Federal do Rio Grande do Sul. Rio Grande do Sul, p.69, 2011.

Couto, S. L. A definição terminológica: problemas teóricos e práticos encontrados na construção de um glossário no domínio da Corrosão. Dissertação (Mestrado em Terminologia e Tradução) - Faculdade de Letras, Universidade do Porto, Porto, 2013.

DISFAGIA. In: Michaelis Dicionário. 2020. Disponível em: <http: / / michaelis.uol.com.br/busca?r=0\&f=0\&t=0\&palavra=disfagiauol .com.br/moderno-portugues/busca/portugues-brasileiro/ausência/>. Acesso em: 22 mai 2020.

DuARTE, V. M. N. Paralelismo - Uma questão de estilo textual. Brasil Escola, 2020. Disponível em: <https://brasilescola.uol.com.br/redacao/paralelismo.htm>. Acesso em: 11 mai 2020.

ETGES, C. L. ET AL. Screening tools for dysphagia: a systematic review. CoDAS, v. 26, n. 5, São Paulo, oct. 2014, pp. 343-349.

FLEISS, J. L. The Design and analysis of clinical experiments. New York: Wiley, 1986.

GIUSTI, E.; BEFI-LOPES, D. M. Tradução e adaptação transcultural de instrumentos estrangeiros para o Português Brasileiro (PB). Pró-Fono, v. 20, n. 3, Barueri, set. 2008, pp. 207-210.

Goncalves, M. I. R.; Remallı, C. B.; Behlau, M. Equivalência cultural da versão brasileira do Eating Assessment Tool - EAT-10. CoDAS, v. 25, n. 6, São Paulo, dez. 2013, pp. 601-604. 
Guillemin, F.; Bombardier, C.; Beaton, D. Cross-cultural adaptation of healthrelated quality of life measures: literature review and proposed guidelines. Journal of Clinical Epidemiology, v. 46, n. 12, Oxford, dec. 1993, pp. 1417-1432.

JeSUS, A. M. R.; BARROS, L. A. Variação terminológica no domínio da Dermatologia: os termos que fazem referencia a nomes de animais. Estudos Linguísticos, v. 34, 2005, pp. 1384-1389.

KERTSCHER, B. ET AL. Bedside screening to detect oropharyngeal dysphagia in patients with neurological disorders: na updated systematic review. Dysphagia, v. 29, n. 2, Germany, apr. 2014, pp. 204-212.

KRIEGER, M. G. A identidade da terminologia e o perfil do terminológo. Revista Trama, v. 2, n. 4, 2006a, pp. 155-164.

KRIEGER, M. G. Do ensino da terminologia para tradutores: diretrizes básicas. Cadernos de Tradução, v. 1, n. 17, 2006b, pp. 190-206.

LEAL, A. B. Funcionalismo e tradução literária: o modelo de Christiane Nord em três contos ingleses contemporâneos. Florianópolis: Scientia Traductionis, 2006.

LUFT, V. C. ET AL. Validation of a new method developed to measure the height of adult patients in bed. Nutriticion in Clinical Practice, v. 23, n. 4, aug./sep. 2008, pp. 424-428.

MAgalhaES JUNIOR, H. V. et AL. Tradução e adaptação transcultural do Northwestern Dysphagia Patient Check Sheet para o português brasileiro. CoDAS, v. 25, n. 4, São Paulo, 2013, pp. 369-374.

MASSAUD, R. M. Afasias. Albert Einstein - Sociedade Beneficente Israelita Brasileira, 2020. Disponível em: <https://www.einstein.br/guiadoencas-sintomas/afasias>. Acesso em: 27 mai 2020.

Neves, F. Imperativo. Norma Culta, 2020. Disponível em: <https://www.normaculta.com.br/imperativo/>. Acesso em: 11 mai 2020a.

Neves, F. Verbos transitivos. Conjugação.com.br, 2020. Disponível em: <https://www.conjugacao.com.br/verbos-transitivos/>. Acesso em: 21 mai 2020b. 
Pagano, A.; MAgalhães, C. M.; AlVes, F. Competência em tradução: cognição e discurso. Editora UFMG, 2005.

PARAguassu, L.; FinatTo, M. J. B. Simplificação, acessibilidade textual e tradução em ambientes multilíngues. Revista GTLex, v. 3, n. 2, p. 251-293, 2020.

Peters, M.; PAsSChIER, J. Translating Instruments for Cross-Cultural Studies in Headache Research. Headache, v. 46, n. 1, St. Louis, jan. 2006, pp. 8291.

REALIZAR. In: Michaelis Dicionário. c2020. Disponível em: <https://michaelis.uol.com.br/moderno-portugues/busca/portuguesbrasileiro/realizar>. Acesso em: 22 mai 2020.

ReICHENHEIM, M. E.; MORAES, C. L. Operationalizing the cross-cultural adaptation of epidemiological measurement instruments. Revista de Saúde Pública, v. 41, n. 4, São Paulo, aug. 2007, pp. 665-673.

ShIEL JUNIOR, W. C. Medical Definition of Dysphasia. MedicineNet. 2018. Disponível em: <https: / /www. medicinenet.com/script/main/art.asp?articlekey=3116 9>. Acesso em: 23 mai 2020.

SHROUT, P. E.; FleISS, J. L. Intraclass correlations: Uses in assessing reliability. Psychological Bulletin, v. 86, n. 2, 1979, pp. 420-428.

SILVA, N. R.; FELIPINI, L. M. G. Tradução e adaptação transcultural de instrumentos de avaliação em Fonoaudiologia para o português brasileiro: uma análise das diretrizes. TradTerm, v. 32, dez. 2018, pp. 32-51.

Sinha, V; Fitzgerald, B. M. Surgical Airway Suctioning. In: StatPearls. Treasure Island (FL): StatPearls Publishing, jan. 2020.

WILD, D. ET AL. Principles of good practice for the translation and cultural adaptation process for patient-reported outcomes (PRO) measures: report of the ISPOR Task Force for translation and cultural adaptation. Value Health, v. 8, n. 2, Malden, mar/apr. 2005, pp. 94-104.

\section{Apêndices}




\section{Apêndice 1}

\section{Protocolo Mann de Avaliação da Habilidade de Deglutição Modificado (MMASA)}

\section{ORIENTAÇÕES:}

Circule os achados clínicos mais adequados para cada item.

Calcule a pontuação total somando os pontos de cada item.

Nome do paciente:

Data:

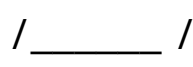

\section{Estado de Alerta}

Tarefa: Observe e avalie a resposta do paciente em relação à fala, à movimentação dos membros ou ao estímulo da dor.

Nota:

$10=$ Alerta.

8 = Nível de atenção/alerta oscilante/sonolência.

5 = Difícil de despertar por meio da fala ou do movimento.

2 = Em coma ou sem resposta.

\section{Cooperação}

Tarefa: Obtenha a atenção do paciente e tente iniciar uma comunicação ou uma atividade.

Nota:

10 = Cooperativo - participa de alguma atividade de interação verbal ou não-verbal.

8 = Cooperação oscilante.

5 = Cooperação relutante.

2 = Não cooperativo/responsivo.

\section{Respiração}

Tarefa: Avalie a condição do sistema respiratório/pulmonar do paciente. 
Nota:

10 = Pulmão limpo, sem evidência clínica ou radiográfica de anormalidade.

8 = Secreção nas vias aéreas superiores ou outra condição/doença

respiratória (ex.: asma/broncoespasmo, doença pulmonar obstrutiva crônica).

6 = Crepitações basais finas/expectoração.

4 = Crepitações basais grossas.

2 = Suspeita de infecção/aspiração frequente/dependência do respirador.

\section{Afasia de Expressão}

Tarefa: Avalie alterações de expressão.

\section{Nota:}

5 = Sem anormalidade.

4 = Dificuldade leve para encontrar palavras/expressar ideias.

3 = Expressa-se de maneira limitada/palavras ou frases curtas.

2 = Ausência de sons funcionais da fala ou produção de palavras isoladas indecifráveis.

1 = Impossível avaliar.

\section{Compreensão Auditiva}

Tarefa: Avalie a habilidade para compreender a comunicação verbal básica.

Nota:

$10=$ Sem anormalidade.

8 = Acompanha uma conversa comum com pouca dificuldade.

6 = Acompanha uma conversa simples/segue instruções repetidas.

4 = Responde ocasionalmente se direcionado.

$1=$ Sem resposta.

\section{Disartria}

Tarefa: Avalie a articulação.

Nota:

5 = Sem anormalidade.

4 = Lenta com imprecisão e ocasional hesitação.

3 = Fala inteligível, mas com ritmo/amplitude articulatória/força/coordenação deficiente. 
2 = Fala ininteligível.

$1=$ Impossivel avaliar.

\section{Saliva}

Tarefa: Observe o controle de saliva do paciente, note qualquer escape de secreção pela lateral da boca.

\section{Nota:}

$5=$ Sem anormalidade.

$4=$ Espumosa/expectorada em um recipiente.

$3=$ Baba algumas vezes durante a fala, quando deitado de lado ou cansado.

$2=$ Um pouco de baba constantemente.

1 = Muita baba, incapaz de controlar a baba.

\section{Movimento da Língua}

Tarefa: Avalie o movimento da língua.

Protrusão: Solicite ao paciente que protrua a língua o máximo possível e, em seguida, a retraia.

Lateralização: Solicite ao paciente que toque cada canto da boca com a língua e, então, repita alternando os movimentos laterais.

Elevação: Com a boca bem aberta, solicite ao paciente que eleve a língua até o palato; alterne entre a elevação e o abaixamento.

Nota:

$10=$ Amplitude total de movimentos/ sem detecção de anormalidade.

8 = Dificuldade leve quanto à amplitude.

$6=$ Movimento incompleto.

$4=$ Movimento mínimo.

$2=$ Nenhum movimento ou incapaz de realizar os movimentos.

\section{Força da Língua}

Tarefa: Avalie a força da língua bilateralmente.

Solicite ao paciente que empurre lateralmente e anteriormente contra um abaixador de língua.

\section{Nota:}

$10=$ Sem anormalidade.

8 = Fraqueza mínima. 
5 = Fraqueza unilateral evidente.

2 = Muita fraqueza ou incapacidade de realizar o movimento.

10. Reflexo de Gag

Tarefa: Solicite ao paciente que toque cada lado da parede posterior da faringe separadamente.

Nota:

5 = Sem anormalidade.

4 = Diminuído bilateralmente.

3 = Diminuído unilateralmente.

2 = Ausente unilateralmente.

1 = Sem reflexo de Gag.

\section{Reflexo de Tosse}

Tarefa: Solicite ao paciente que tussa o mais forte possível.

Observe a força e a qualidade da tosse.

\section{Nota:}

$10=$ Sem anormalidade.

8 = Tosse, mas de qualidade rouca.

5 = Tentativa inadequada.

2 = Sem tentativa ou incapaz de tossir.

\section{Palato}

Tarefa: Solicite ao paciente que produza um “ah" forte, por várias vezes, e sustente cada um por vários segundos.

Observe o movimento de elevação do palato e se há hipernasalidade.

\section{Nota:}

$10=$ Sem anormalidade.

8 = Pequena assimetria observada; palato móvel.

6 = Fraqueza unilateral e sustentação inconsistente.

4 = Movimento mínimo, regurgitação nasal, escape de ar nasal.

2 = Sem elevação do palato ou incapaz de realizar o movimento. 
PONTUAÇÃO MMASA =

Interpretação

Pontuação $\geq 95$ : Inicie dieta oral e progrida conforme tolerado. Monitore a primeira ingestão oral e consulte um FONOAUDIÓLOGO se o paciente apresentar dificuldade em comer ou beber.

Pontuação $\leq$ 94: Não administre qualquer dieta por via oral e consulte um FONOAUDIÓLOGO para uma avaliação formal da deglutição. 